the squirrel fishes (Holocentridae), mainly shallow water tropical fishes. Again, many taxonomic problems were evident in this group which Woods and Sonoda have clarified. It is comforting to see such a troublesome spectre as Hoplostethus islandicus of German fishery workers finally laid as a junior synonym of $H$. atlanticus!

The contributions of Marshall and Iwamoto have brought together the widespread literature on the rat-tails (Macrouridae) in a way which will facilitate the identification of these difficult fishes. An elucidation of this group is particularly timely as the rattails, the dominant fish group of the lower continental shelf, are becoming increasingly attractive as commercial fishes. Russian exploitation of the northern Coryphaenoides rupestris has already reached considerable proportions and wider interest in this relatively well-flavoured fish can be predicted.

Alwyne Wheeler

\section{Taxonomy without genes}

Numerical Taxonomy. The Principles and Practice of Numerical Classification. By Peter H. A. Sneath and Robert R. Sokal. Pp. xv +573 . (A series of Books in Biology.) (Freeman: San Francisco, October 1973.) $£ 9.40$.

THIs is not a second edition of Sokal and Sneath's well known 1963 book on numerical taxonomy but a completely new work. The authors' aim is to provide a comprehensive and up to date account of the subject and to illustrate the advantages of numerical over conventional taxonomy.

It is certainly a very careful and detailed review, and will be of great value to anyone with a professional interest in this field. It is not a book for someone wishing to 'find out about numerical taxonomy'. Readers are referred to the original papers for many of the details and the mathematical notation, although logical and consistent, produces such mind-bending conjunctions as

$$
t_{\mathbf{J}, 1 i}=\sum_{i \mathbf{J}}^{t} \mathbf{X}_{i \mathrm{j} J} .
$$

When these ingredients are added to the already gross terminology of conventional taxonomy the result is hard going even for people experienced in the field.

The first three chapters on taxonomic principles and evidence provide the background for the rest of the book. The choice and coding of characters is discussed and the authors make it clear that this is the least satisfactory aspect of numerical taxonomy. Chapters 4 and 5 on taxonomic resemblance and structure form the core of the book and chapter 6 deals with methods of esti- mating cladistic relationships. This last should be particularly useful as it collects together, for the first time, a lot of recently published material. There is a chapter on identification, including the automatic generation of keys; a chapter on populations; a chapter on nomenclature; and a few bits and pieces. The bibliography is vast and there is also a list of applications of numerical taxonomy to systematics classified by the group of organisms. An author and subject index ends the book.

The authors' basic position (highly paraphrased) is that a purely phenetic classification system would have great advantages for biology in general. Genetic and phylogenetic information should be irrelevant to the classification (however interesting in its own right). Old ideas about phenetic resemblance estimating genetic resemblance have been thrown overboard and the good ship SS Phenetics is now sailing under its true colours. The authors accept that the lack of a satisfactory definition of 'character' is a theoretical weakness, but claim a certain robustness in practice. They also state that, in time, numerical taxonomy will become objective, and criteria for grouping will be agreed by common consent.

The very size and complexity of the book makes this last claim seem unlikely. A tremendous variety of techniques is mentioned and each new alternative to some act which was previously without alternative doubles the number. It may be that a book such as this is an essential first step-an inventory before taking the vote; but it seems to me more likely that what will emerge from numerical taxonomy is a set of very useful mathematical methods but no general agreement about the way in which the results of applying them should be used.

Whether one is sympathetic to the aims of numerical taxonomy or not it must be granted that to have written a book as up to date and comprehensive as this is a remarkable achievement. It, will be an indispensible reference work for many years to come, proving useful to all taxonomists, not just those who obey the fiat of pheneticism.

\section{Hills}

\section{Mineral metabolism}

Calcium and Phosphorus Metabolism. By J. T. Irving. $\mathrm{Pp}$ viii +246 . (Academic (Harcourt Brace Jovanovich): New York and London, September 1973.) $£ 15$.

INTEREST in this book is quickly aroused by. its table of contents since almost. every aspect of the subject is covered in an orderly and well-tabulated progression. The style is readable and there is no difficulty in locating particular topics of interest. The book is reasonably elementary, its depth being necessarily limited by its size, but so much recent knowledge has accumulated, for example with respect to the chemistry of parathyroid hormone, to cyclic AMP and to vitamin $\mathrm{D}$ metabolism, that a simple overview such as this is timely. The author might perhaps have made still more use of the opportunities for critical judgment that a monograph provides but attempts to reconcile conflicting evidence are nevertheless made in a rational way. While the overall approach of the book is physiological, biochemical and clinical aspects are interwoven.

The revision for this edition is a little uneven and a few sections are still composed from largely primitive sources. Occasional statements are misleading such as the bald comment that "in myxoedema the level (of blood calcium) is unchanged". The disadvantage of long publication time is apparent particularly in the expanding field of vitamin $\mathrm{D}$ metabolism where the most recent references are over 2 years old. Nevertheless this remains an excellent, concise book for students of the field and will also be of value to specialists when they require to look into other physiological aspects of their subject.

T. C. B. Stamp

\section{Ukrainian hunters}

Ice-Age Hunters of the Ukraine: Prehistoric Archaeology and Ecology. By Richard Klein. Pp. xviii +140 . (Universit,y of Chicago: Chicago and London, 1973.) $£ 2.95$ boards; $£ 1.35$ paper.

THis small book serves two purposes. First it is a very welcome up to date summary of Soviet research in the upper Palaeolithic of the Ukraine, and, second, it makes available material not readily accessible to Western readers who do not read Russian fluently.

The author takes the occupation of the Ukraine during the Last Glaciation, roughly from about 45,000 to 10,000 years, which covers the Mousterian as well as the Upper Palaeolithic.

The preface and the early sections suggest that the author has undergraduates in mind and this has had some effect on the whole tone of the book, but this approach in no way detracts from its usefulness. Both the archaeology and the supporting studies, geology, fauna and pollen studies, are dealt with in some detail with the result that the area and period are dealt with as a whole, including discussion of the environments during the three stages of the Last Glaciation. This evidence is illustrated by maps, pollen diagrams and faunal lists.

The archaeological side, which is the main purpose of the book, deals very fully with the evidence for dwelling 